\title{
Strength of Si-H. . B B charge-inverted hydrogen bonds in 1-silacyclopent-2-enes and 1-silacyclohex-2-enes
}

\author{
Mirosław Jabłoński ${ }^{1}$ (D)
}

Received: 10 February 2017 / Accepted: 8 March 2017 / Published online: 23 March 2017

(C) The Author(s) 2017. This article is published with open access at Springerlink.com

\begin{abstract}
It is shown that the $\mathrm{H} \cdots \mathrm{B}$ contacts in 1silacyclohex-2-enes are clearly stabilizing and strong, whereas those in 1-silacyclopent-2-enes are much weaker. This result is supported by analysis of QTAIM-based parameters and appropriate structural changes taking place upon the open form $\rightarrow$ closed form transformation and is in full agreement with previous NMR spectroscopic data [Wrackmeyer et al. (2006) Appl Organometal Chem 20:99105]. Also, the influence of electronic and steric effects originating from the presence of specific substituents on the strength of the $\mathrm{H} \cdots \mathrm{B}$ contacts is discussed in detail. Some problems and ideas associated with the use of the so-called open-closed method utilized in assessing values of interaction energies are discussed in detail. Particular attention is paid to the correct choice of reference open systems. It is shown that their partial geometry optimization leads to reliable values of interaction energies.
\end{abstract}

Keywords Charge-inverted hydrogen bond . Triel bond . Silicon · Boron · Interaction energy · Intramolecular interaction $\cdot$ DFT $\cdot$ PBE0 $\cdot$ Molecular modeling

\section{Introduction}

Wrackmeyer is most likely the first who paid attention to the presence and the bonding character of a $\mathrm{Si}-\mathrm{H}-\mathrm{B}$ bridge

Mirosław Jabłoński

teojab@chem.uni.torun.pl

1 Department of Quantum Chemistry, Faculty of Chemistry, Nicolaus Copernicus University in Toruń, 7-Gagarina St., 87-100 Toruń, Poland in organoboron compounds [1-4]. The role of this bridge in the formation of heterocyclic systems containing both silicon and boron atoms was discussed on the basis of both NMR and IR spectroscopic data [1]. Also, the presence of a $\mathrm{Si}-\mathrm{H}-\mathrm{B}$ bridge in 3-bora-4-methylene-homoadamantane was determined on the basis of $\mathrm{X}$-ray structural measurements [2]. More importantly for the present article, based on the NMR spectra obtained for two members ( $\mathbf{1}$ and $\mathbf{2}$ in Fig. 1) of 1-silacyclopent-2-enes, Wrackmeyer et al. [4] have concluded that $\mathrm{Si}-\mathrm{H}-\mathrm{B}$ bridges in these molecules are either absent or extremely weak. This was to be in opposition to their 1-silacyclohex-2-ene counterparts ( 3 and $\mathbf{4}$ in Fig. 1), where existences of $\mathrm{Si}-\mathrm{H}-\mathrm{B}$ bridges have been confirmed by similar spectroscopic data [4]. This difference in $\mathrm{Si}-\mathrm{H}-\mathrm{B}$ bonding effect was attributed to stronger repulsion between silyl groups in both 1-silacyclohex-2-enes forcing the exocyclic relevant silyl group to approach closer to the 9-borabicyclo[3.3.1]nonane group (9-BBN) and, as a consequence, considerably reducing the $\mathrm{H} \cdots \mathrm{B}$ distance.

Bonding properties of the $\mathrm{Si}-\mathrm{H} \cdots \mathrm{Y}$ bridge are well known [5-9]. For example, in case of $\mathrm{Y}$ being a transition metal, this interaction is called an agostic bond [10-13] or a $\sigma$ interaction [12-17] depending on a specific situation, whereas if $\mathrm{Y}$ is an electron-deficient element (as, for example, boron), this type of interaction was called a "charge-inverted hydrogen bond" (CIHB) [11-13, 18-25]. Therefore, the electron-deficient $\mathrm{Si}-\mathrm{H}-\mathrm{B}$ bridge (this term was being used by Wrackmeyer et al. [1-4]) in investigated systems in fact represents one of the examples of intramolecular charge-inverted hydrogen bonds (IMCIHB).

Taking the above into account, it is really a tempting challenge to assess strengths of $\mathrm{H} \cdots \mathrm{B}$ interactions in $\mathbf{3}$ and $\mathbf{4}$, and particularly in $\mathbf{1}$ and $\mathbf{2}$. It can be done by computing values of the interaction energy of $\mathrm{H} \cdots \mathrm{B}$. Although this energetical parameter is not accessible to experimental 
Fig. 1 Structural formulas of 1-silacyclopent-2-enes and 1silacyclohex-2-enes investigated by Wrackmeyer et al. [4]

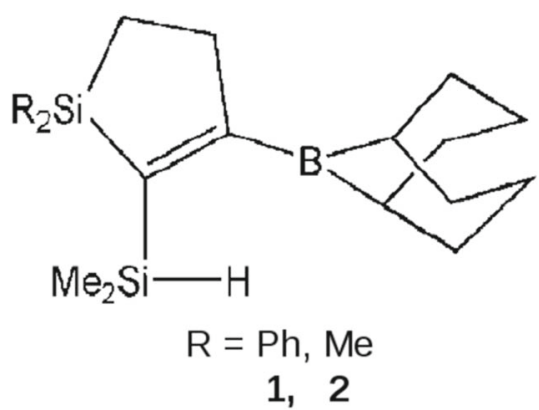

measurements, it is relatively easily accessible to theoretical methods of molecular modeling. As widely believed, the interaction energy directly describes the strength of a (local) intramolecular interaction. Taking into account the NMR spectroscopic data obtained by Wrackmeyer et al. [4], one should expect clearly negative, i.e. showing stabilizing character of $\mathrm{H} \cdots \mathrm{B}$, values of interaction energies obtained for both 1-silacyclohex-2-enes, i.e. 3 and $\mathbf{4}$, whereas for both 1-silacyclopent-2-enes ( $\mathbf{1}$ and $\mathbf{2}$ ), they should be either positive or only slightly negative. In the former case, our results would suggest repulsive character of the $\mathrm{H}$. . B contact, whereas in the latter, this contact would be weakly bonding. In addition to these four molecules investigated earlier by Wrackmeyer et al. [4] (Fig. 1), we also have performed similar computations for their simplified derivatives (see the 'Investigated systems' section). This approach allows us to discuss influence of both electronic and steric effects originating from the presence of specific substituents on the strength of investigated $\mathrm{Si}-\mathrm{H}$. . B bridges.

The other purpose of this article is to shed light on some problems relating to the definition of the interaction energy (of an intramolecular $\mathrm{H}$.. Y contact) itself. In particular, an importance of the choice of a reasonable reference open system will be discussed in detail, showing that this is not so easily-done task as it might at first seem. In our opinion, this issue is not raised often enough [19, 26-31].

\section{Computational methodology}

Geometry optimizations and frequency calculations to analyze characters of obtained stationary points have been performed using Gaussian 09 program [32]. Lack of imaginary frequencies has confirmed that obtained geometries correspond to local minima on the potential energy hypersurface. For some reference systems, also, partial geometry optimizations have been performed as indicated in the text. Analysis of the topology of the electron density distribution has been made by means of quantum theory of atoms in molecules (QTAIM) [33-35] using the AIMAll package [36]. All calculations have been performed utilizing the
PBE0 [37-39] exchange-correlation functional of density functional theory and the $6-311 \mathrm{G}(\mathrm{d}, \mathrm{p})$ basis set $[40,41]$. It was shown that PBE0 gives reasonable molecular structures $[12,42]$ as well as electronic densities $[43,44]$. On the other hand, the 6-311G(d,p) basis set is of valence triple zeta quality and, additionally, includes polarization functions for all atoms.

\section{Energy of an intramolecular interaction}

In contrast to the energy of an intermolecular interaction (e.g. a hydrogen bond), the energy of an intramolecular interaction is not a definable quantity due to the fact that any attempt of extracting the energy of the interaction of interest from the total energy of a system hosting this interaction introduces high degree of discretion for the choice of a reference system [27-31]. Nevertheless, in spite of this, some additive schemes leading to numbers understood as interaction energies have been proposed. Among them, the so-called open-closed method $[45,46]$ seems to be both the most popular [26-29, 45-58] and straightforward. According to this method, the interaction energy is just a difference between total energies of the closed form of a molecule, i.e. the form hosting the relevant interaction, and the open one obtained by a proper rotation of either the donor or the acceptor group and, as a consequence, characterized by a cleavage of the relevant interaction (see Fig. 2).

It is understood that in general different interaction energy values are obtained as a result of different reference open systems used [28].

What is more, having one of these open systems already chosen, one encounters a new question, namely whether or not the geometry of the open system should be fully optimized [28, 58]. Unfortunately, only in a small piece of articles where the open-closed method is utilized, this question is addressed [19, 28, 29, 45, 46, 58]. Most likely, Schuster was the first who suggested [45] to use the open form having 'the least changes in molecular geometry besides a cleavage of the $\mathrm{H}$-bond" pointing out that the open reference system 'need not be a local minimum of the energy surface` [46]. In his opinion, performing single-point 


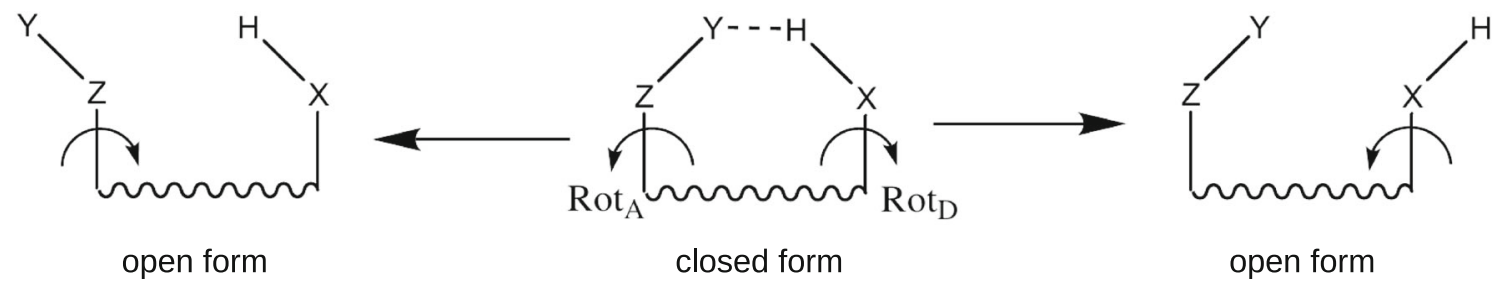

Fig. 2 Scheme presenting a method for receiving open reference forms in the open-closed method defining the energy of intramolecular interaction (indicated by dashed line) in the closed form

calculations for the open form 'seems to be more appropriate' than the full geometry optimization of the open reference form 'in cases where it can be applied, because it does not mix a large energy of isomerization into the $\mathrm{H}$ bond energy“ [46]. Schuster underlined, however, that any splitting of the change in total energy into pure isomerization and H-bond energy is artificial in fact [46]. As already mentioned, acceptance of this approach leads to single-point energy calculations for the open form, for which all geometry parameters (but a rotation angle of course) are taken from the closed form and then kept constant (i.e. frozen). This situation is depicted on the left hand side of Fig. 3, where $E_{\mathrm{c}}$, $E_{\mathrm{o}}^{\mathrm{f}, \mathrm{c}}$ and $E_{\mathrm{c}}^{\mathrm{f}}$ mean total energies of closed, fictitious open and fictitious closed forms, respectively. It should be noted that this approach is in line with the definition of the intermolecular interaction energy, $\Delta E_{\mathrm{int}}=E(\mathrm{AB})-E(\mathrm{~A})-$ $E(\mathrm{~B})$, where individual monomers $\mathrm{A}$ and $\mathrm{B}$ have geometries from the complex $\mathrm{AB}$.

On the contrary, the other approach, which nowadays seems to be a standard procedure [57], in the open-closed method arises if the full geometry optimization (rather than single-point calculations) of the open form is performed (leading to $E_{0}$; Fig. 3). This approach takes into account the fact that the geometry (structure) change that takes place

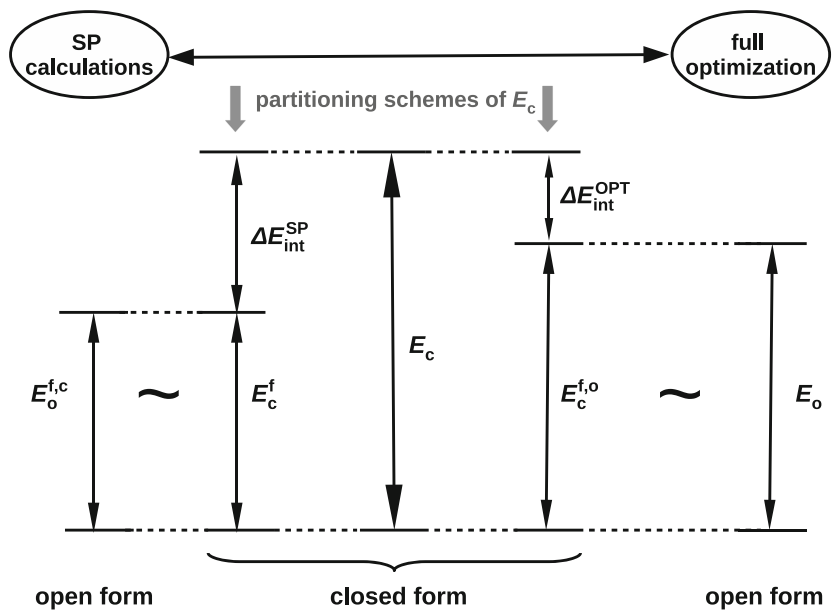

Fig. 3 Scheme showing two models of the partition of the total energy of the interaction-hosting molecule $\left(E_{\mathrm{c}}\right)$ to the energy of the interaction and the total energy of a fictitious molecule obtained by 'exclusion' of this interaction upon the open form $\rightarrow$ closed form transformation is a consequence of the relevant interaction. In other words, the geometry of the interaction-hosting system is marked by the presence of this interaction. In the picture of intermolecular interactions, this approach corresponds to fully isolated monomers $\mathrm{A}$ and $\mathrm{B}$ possessing their own geometries. In this case, $\Delta E_{\text {int }}$ would include deformation energies as well. More precisely, both these $\Delta E_{\text {int }}$ values in fact correspond to different energy parameters-interaction and binding energies, respectively. Similarly, in the case of intramolecular interactions, both approaches introduce in fact different definitions of the interaction energy-parameter that- to remind-is in fact not strictly defined by quantum chemistry [29-31]. Both these definitions of the (intramolecular) interaction energy correspond to different partition schemes of the total energy of the closed form as shown in Fig. 3. Of course, $\left|E_{\mathrm{o}}\right|>\left|E_{\mathrm{o}}^{\mathrm{f}, \mathrm{c}}\right|$ and hence, one should observe that $\Delta E_{\text {int }}^{\mathrm{OPT}}<\Delta E_{\text {int }}^{\mathrm{SP}}$.

At this point, one encounters a new problem. Quite often reference open systems have new important interactions (either attractive or repulsive) [27-31, 51-53]. As a consequence, one obtains either under- $\left(\Delta E_{\text {int,a }}^{\mathrm{OPT}}\right)$ or overestimated $\left(\Delta E_{\mathrm{int}, \mathrm{r}}^{\mathrm{OPT}}\right)$ values of interaction energies, respectively, as shown in Fig. 4. Some examples will be discussed later.

Moreover, in many instances, the structure of the fully optimized open form may also be considerably different than that of the closed form. This case can be manifested by significantly different values of bond lengths and of plane or dihedral angles. For example, Buemi et al. [28] rebuked the use of the most extended enol and enethiol tautomers of thiomalondialdehyde as reference structures [27] since the trans configuration of double bonds seems to be too different than the cis one in the closed form. It is easy to imagine other examples. The amino group is usually somewhat pyramidal, whereas it becomes flat in closed form featuring conjugated system of double bonds as, e.g. in 3-aminoprop2-enal. Boryl $-\mathrm{BH}_{2}$ group may be perpendicular (or nearly so) to the molecular chain in closed form, whereas, on the contrary, it may be in plane in the open one. It will be shown that the latter happens if the 9-BNN group is substituted by $\mathrm{BH}_{2}$. It is seen from Fig. 4 that too attractive interaction(s) in the open reference form or its significantly extended structure can even lead to changed sign of the interaction energy [19]. 


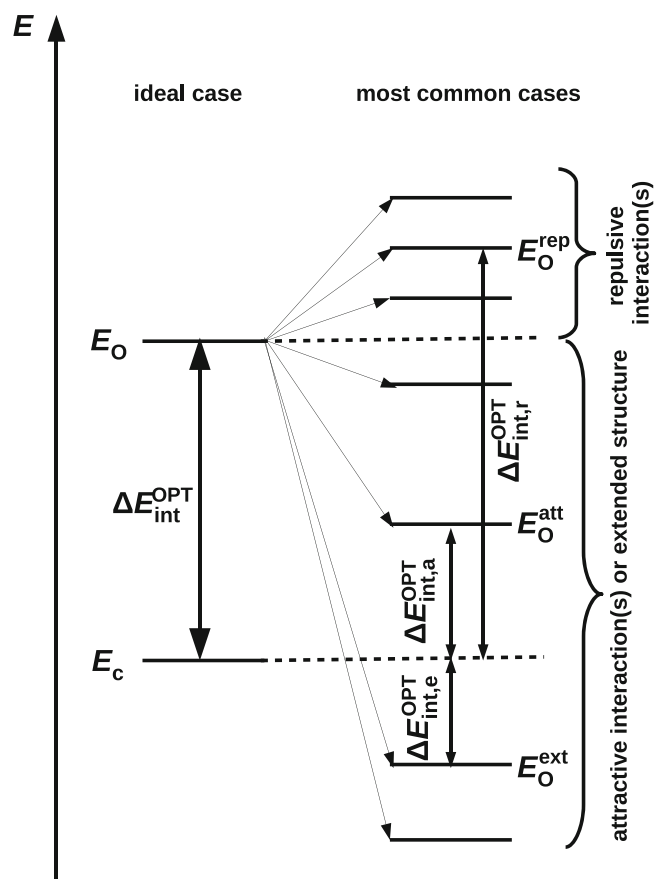

Fig. 4 Unreliable estimates of the interaction energy in the openclosed method obtained due to additional repulsive or attractive interactions or extended structure of the reference open form

Taking the above into account, we proposed [19] performing partial (i.e. constrained) geometry optimization in such cases, where one freezes only those geometric parameters whose optimization would lead to either some new important interactions or to considerably different structures. Although in most cases, it is sufficiently to freeze one or two dihedral angles that determine positions of donor and acceptor groups, sometimes, it is necessary to freeze other geometrical parameters as well. Of course, the full geometry optimization of the open form may still be performed if only it will not lead to any new important interactions or considerable structural changes in at least some parts of the molecule. The idea of performing constrained geometry optimization of the open reference form [19] is also utilized in our estimates of interaction energies of $\mathrm{H} \cdots \mathrm{B}$.

\section{Investigated systems}

Initial calculations have been performed for 9-(2-(dimethylsilyl)-1,1-diphenyl-1-silacyclopenta-2-en-3yl)-9-borabicyclo(3.3.1)nonane (1 in Fig. 1) utilizing its experimental structure determined from X-ray crystalographic measurements [4] and available via Cambridge Structural Database [59] as MEDSUK (1 $\left.\mathbf{A}_{\text {exp }}\right)$. Also, its analogue with $-\mathrm{SiMe}_{2} \mathrm{H}$ rotated about the $\mathrm{Si}-\mathrm{C}$ bond has been used as a reference molecule $\left(\mathbf{1 a}_{\exp }\right)$. Their fully optimized analogues are labelled as $\mathbf{1 A}$ and $\mathbf{1 a}$, respectively.
Since experimental structures of $\mathbf{2 , 3}$ and $\mathbf{4}$ have not been determined, fully optimized geometries of both open and closed forms of these molecules have been obtained (2A, 3A, 4A and 2a, 3a, 4a, respectively). Although used for computing $v_{\mathrm{SiH}}$ frequency shifts, 1a, 2a, 3a and 4a have, however, been found as being not fully correct references for interaction energies. Instead, reference open systems obtained after partial (see further text) geometry optimizations have been used (symbols with prime). Eventually, similar calculations for some derivatives of all these systems have also been performed. Letter 'B' (or 'b') has been used if the $-\mathrm{SiMe}_{2} \mathrm{H}$ group has been substituted by $-\mathrm{SiH}_{3}$, 'C' (or 'c') if 9-BBN has been substituted by $-\mathrm{BMe}_{2}$, and 'D' (or 'd') if 9-BBN has been substituted by $-\mathrm{BH}_{2}$ (see Fig. 5).

Similar as for $\mathbf{1 A}, \mathbf{2 A}, \mathbf{3 A}$ and $\mathbf{4 A}$, partially rather than fully optimized open forms have been used for estimations of interaction energies of $\mathrm{H} \cdots \mathrm{B}$ contacts in the closed forms. For the reasoning of their use, see the 'Energy of an intramolecular interaction' section and discussion of results. Structures of fully optimized forms of all investigated systems as well as their open forms used as references for the interaction energy estimates are shown in Fig. 6.

\section{Results and discussion}

Discussed values of most important geometric parameters relating to the HSiCCB quasi-ring in open and closed forms of investigated systems are gathered in Table 1.

Local deformations of structure are determined by parameters $P, \theta_{\mathrm{HSiCC}}^{\mathrm{def}}, \theta_{\mathrm{HSiCSi}}^{\mathrm{def}}$ and $\theta_{\mathrm{SiCCB}}$, where $P$, that can be called as pyramidalization parameter [25] of the trigonal boryl subunit, is just a difference between the round angle and the sum of all $E_{1}-B-E_{2}$ (where $E_{1}$ and $E_{2}$ is $C$ or $H$ ) angles in this subunit, $\theta_{\mathrm{HSiCC}}^{\mathrm{def}}$ and $\theta_{\mathrm{HSiCSi}}^{\mathrm{def}}$ are deformation angles showing positional deviation of the $\mathrm{H}$ atom from the plane (for closed forms: $\theta_{\mathrm{HSiCC}}^{\mathrm{def}}=\theta_{\mathrm{HSiCC}}$ and $\theta_{\mathrm{HSiCSi}}^{\mathrm{def}}=$

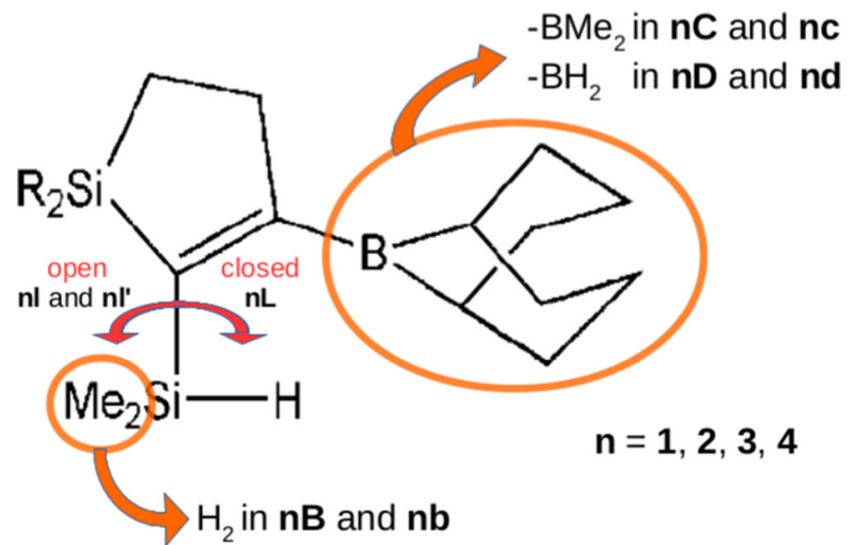

Fig. 5 Symbols introduced for the considered molecules 


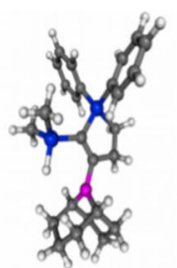

$1 \mathrm{~A}$

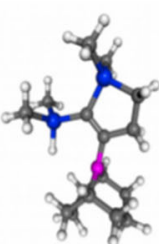

2A

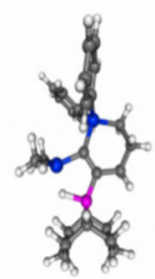

$3 A$

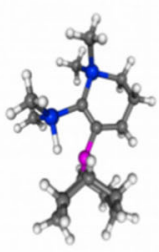

4A

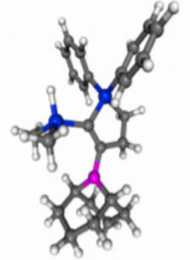

$1 a^{\prime}$

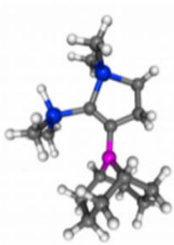

$2 a^{\prime}$

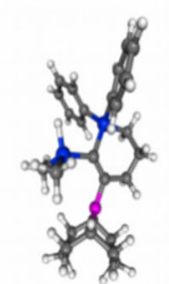

$3 a^{\prime}$

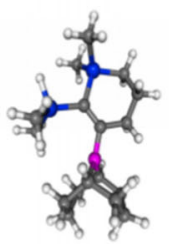

$4 a^{\prime}$

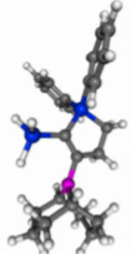

1B

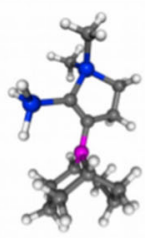

2B

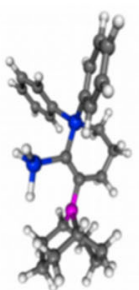

3B

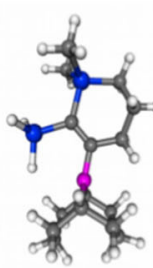

4B
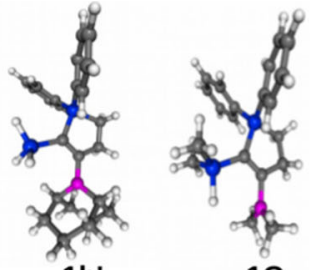

1C

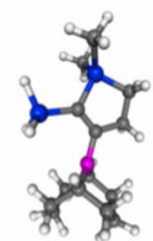

2b'

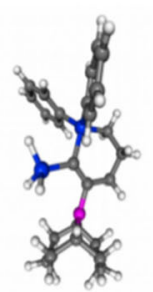

3b'

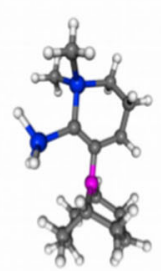

4b'

2C

3C

4C

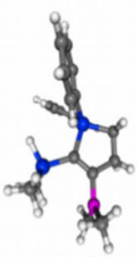

$1 c^{\prime}$
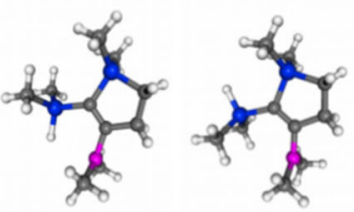

2c'
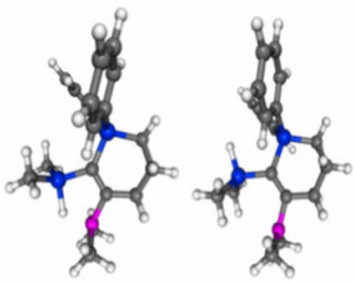

$3 c^{\prime}$
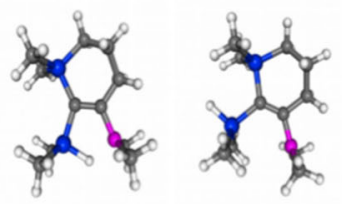

$4 c^{\prime}$

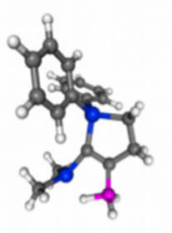

1D

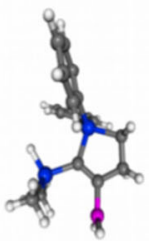

1d'
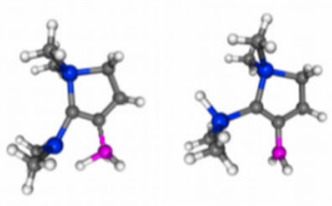

2D

$2 d^{\prime}$

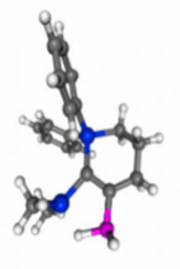

3D

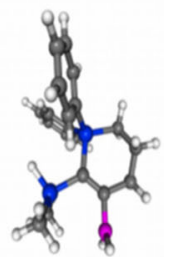

3d'
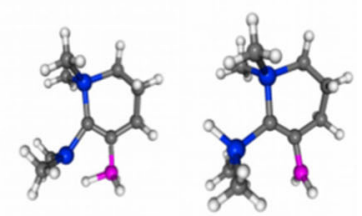

4D

4d'

Fig. 6 Fully optimized closed and partially optimized open forms of investigated molecules

$180^{\circ}-\theta_{\mathrm{HSiCSi}}$, for open forms: $\theta_{\mathrm{HSiCC}}^{\mathrm{def}}=180^{\circ}-\left|\theta_{\mathrm{HSiCC}}\right|$ and $\left.\theta_{\mathrm{HSiCSi}}^{\mathrm{def}}=\left|\theta_{\mathrm{HSiCSi}}\right|\right)$, and $\theta_{\mathrm{SiCCB}}$ is just the $\mathrm{Si}-\mathrm{C}-\mathrm{C}-\mathrm{B}$ dihedral angle. Since in all primed systems, the $\theta_{\mathrm{HSiCC}}$ angle has been taken as $180^{\circ}$ and then kept constant, the value of $0^{\circ}$ for $\theta_{\mathrm{HSiCC}}^{\mathrm{def}}$ for all these systems is a direct consequence of partial geometry optimization.

\section{General features of closed forms}

We begin analysis of our results shown in Table 1 on changes taking place upon the open form $\rightarrow$ closed form transformation, i.e when the $\mathrm{Si}-\mathrm{H}$. B B bridge is formed. It is clearly seen that formation of this bridge leads to shorter $\mathrm{Si}$.. B distances and longer $\mathrm{Si}-\mathrm{H}$ bonds. Elongations of $\mathrm{Si}-\mathrm{H}$ are accompanied by red-shifts of $\nu_{\mathrm{SiH}}$. Moreover, more significant pyramidalization of the boryl fragment is observed as well. All these effects are geometrical evidences of bonding character of $\mathrm{H}$. . B contacts in the closed forms. This result is then confirmed by negative values of interaction energies. Only in case of $\mathbf{n B}(\mathbf{n}=\mathbf{1 - 4})$ systems the bonding character of $\mathrm{H}$... B may be uncertain if one takes into account that the error of the open-closed method may be of the order of some $1-2 \mathrm{kcal} / \mathrm{mol}$. Clearly, however, the bonding character of the $\mathrm{SiH}$. . B bridge is considerably weakened if the $-\mathrm{SiMe}_{2} \mathrm{H}$ group is substituted by the $-\mathrm{SiH}_{3}$ one. Conversely, compared to $-\mathrm{SiH}_{3}$, the $-\mathrm{SiMe}_{2} \mathrm{H}$ group leads to stronger $\mathrm{H}$. . B interaction. This most likely is due to the electron-donating properties of the methyl group.

\section{1-Silacyclopent-2-enes vs 1-silacyclohex-2-enes}

The main purpose of this article is to assess the strength of $\mathrm{Si}-\mathrm{H}$. . B bridges in 1-silacyclopent-2-enes and to compare them to those obtained for similar 1-silacyclohex-2-enes (Fig. 1). As already mentioned in the 'Introduction' section, on the basis of NMR spectroscopic data, Wrackmeyer et al. [4] have concluded that in the former group, the $\mathrm{Si}-\mathrm{H} \cdots \mathrm{B}$ bridges are either absent or extremely weak, whereas, in the latter, $\mathrm{Si}-\mathrm{H}$. . B bridges have been said to exist.

Our estimation of the interaction energy of the $\mathrm{Si}-\mathrm{H} \cdots \mathrm{B}$ bridge in $\mathbf{1} \mathbf{A}_{\text {exp }}$ gave $-6.6 \mathrm{kcal} / \mathrm{mol}$-quite large value considering, e.g. relatively long H. . B distance (2.647 $\AA$ ), 
Table 1 Values of most important geometric parameters relating to the HSiCCB quasi-ring (bond distances in $\AA$, angles and $P$ in degrees), harmonic stretching vibration frequency of $\mathrm{Si}-\mathrm{H}\left(\mathrm{in}_{\mathrm{cm}}^{-1}\right.$ ), estimated value of the interaction energy of the $\mathrm{H} \cdots \mathrm{B}$ contact (in $\mathrm{kcal} / \mathrm{mol}$ )

\begin{tabular}{|c|c|c|c|c|c|c|c|c|c|c|c|}
\hline System & $d_{\mathrm{Si} \cdots \mathrm{B}}$ & $d_{\mathrm{SiH}}$ & $d_{\mathrm{H} \cdots \mathrm{B}}$ & $\alpha_{\mathrm{SiHB}}$ & $P$ & $\theta_{\mathrm{HSiCC}}^{\mathrm{def}}$ & $\theta_{\mathrm{HSiCSi}}^{\mathrm{def}}$ & $\theta_{\mathrm{SiCCB}}$ & $v_{\mathrm{SiH}}$ & $\Delta v_{\mathrm{SiH}}{ }^{\mathrm{a}}$ & $\Delta E_{\mathrm{int}}$ \\
\hline $\mathbf{1} \mathbf{A}_{\exp }$ & 3.224 & 1.325 & 2.647 & 103.4 & 1.1 & 9.7 & 8.1 & 0.7 & 2083 & $\mathrm{n} / \mathrm{a}$ & -6.6 \\
\hline $\mathbf{1 A}$ & 3.276 & 1.504 & 2.712 & 97.8 & 1.1 & 9.9 & 7.2 & 3.6 & 2151 & -34 & -2.6 \\
\hline 1a' & 3.502 & 1.496 & $\mathrm{n} / \mathrm{a}$ & $\mathrm{n} / \mathrm{a}$ & 0.8 & $0.0^{\mathrm{b}}$ & 4.1 & 8.6 & $\mathrm{n} / \mathrm{a}$ & $\mathrm{n} / \mathrm{a}$ & $\mathrm{n} / \mathrm{a}$ \\
\hline $1 B$ & 3.304 & 1.496 & 2.857 & 93.5 & 0.9 & 9.5 & 15.3 & 0.3 & 2199 & $\mathrm{n} / \mathrm{c}^{\mathrm{c}}$ & -0.7 \\
\hline $1 b^{\prime}$ & 3.354 & 1.490 & $\mathrm{n} / \mathrm{a}$ & $\mathrm{n} / \mathrm{a}$ & 0.3 & $0.0^{\mathrm{b}}$ & 1.2 & 6.9 & $\mathrm{n} / \mathrm{a}$ & $\mathrm{n} / \mathrm{a}$ & $\mathrm{n} / \mathrm{a}$ \\
\hline $1 \mathrm{C}$ & 3.300 & 1.504 & 2.744 & 97.6 & 0.2 & 7.9 & 3.8 & 2.6 & 2147 & -39 & -2.6 \\
\hline $1 c^{\prime}$ & 3.484 & 1.496 & $\mathrm{n} / \mathrm{a}$ & $\mathrm{n} / \mathrm{a}$ & 0.1 & $0.0^{\mathrm{b}}$ & 6.4 & 5.5 & $\mathrm{n} / \mathrm{a}$ & $\mathrm{n} / \mathrm{a}$ & $\mathrm{n} / \mathrm{a}$ \\
\hline $1 D$ & 2.526 & 1.599 & 1.405 & 114.4 & 9.9 & 1.8 & 6.2 & 1.7 & 1849 & -334 & -10.3 \\
\hline 1d' & 3.354 & 1.495 & $\mathrm{n} / \mathrm{a}$ & $\mathrm{n} / \mathrm{a}$ & $0.0^{\mathrm{b}}$ & $0.0^{\mathrm{b}}$ & 4.7 & 2.4 & $\mathrm{n} / \mathrm{a}$ & $\mathrm{n} / \mathrm{a}$ & $\mathrm{n} / \mathrm{a}$ \\
\hline $2 A$ & 3.253 & 1.503 & 2.672 & 98.4 & 1.1 & 6.0 & 8.5 & 1.3 & 2154 & -12 & -1.7 \\
\hline $2 a^{\prime}$ & 3.491 & 1.499 & $\mathrm{n} / \mathrm{a}$ & $\mathrm{n} / \mathrm{a}$ & 0.7 & $0.0^{\mathrm{b}}$ & 1.7 & 6.3 & $\mathrm{n} / \mathrm{a}$ & $\mathrm{n} / \mathrm{a}$ & $\mathrm{n} / \mathrm{a}$ \\
\hline $2 B$ & 3.310 & 1.496 & 2.851 & 94.0 & 0.9 & 3.6 & 7.5 & 0.0 & 2195 & $\mathrm{n} / \mathrm{c}^{\mathrm{c}}$ & -0.5 \\
\hline $2 b^{\prime}$ & 3.331 & 1.493 & $\mathrm{n} / \mathrm{a}$ & $\mathrm{n} / \mathrm{a}$ & 0.4 & $0.0^{\mathrm{b}}$ & 2.8 & 5.7 & $\mathrm{n} / \mathrm{a}$ & $\mathrm{n} / \mathrm{a}$ & $\mathrm{n} / \mathrm{a}$ \\
\hline $2 \mathrm{C}$ & 3.217 & 1.505 & 2.619 & 99.0 & 0.6 & 4.8 & 6.9 & 0.7 & 2141 & -27 & -2.1 \\
\hline $2 c^{\prime}$ & 3.444 & 1.499 & $\mathrm{n} / \mathrm{a}$ & $\mathrm{n} / \mathrm{a}$ & 0.3 & $0.0^{\mathrm{b}}$ & 0.1 & 2.4 & $\mathrm{n} / \mathrm{a}$ & $\mathrm{n} / \mathrm{a}$ & $\mathrm{n} / \mathrm{a}$ \\
\hline $2 D$ & 2.518 & 1.598 & 1.403 & 114.0 & 9.9 & 0.3 & 2.5 & 0.1 & 1851 & -318 & -9.7 \\
\hline 2d' & 3.352 & 1.498 & $\mathrm{n} / \mathrm{a}$ & $\mathrm{n} / \mathrm{a}$ & $0.0^{\mathrm{b}}$ & $0.0^{\mathrm{b}}$ & 2.1 & 0.3 & $\mathrm{n} / \mathrm{a}$ & $\mathrm{n} / \mathrm{a}$ & $\mathrm{n} / \mathrm{a}$ \\
\hline $\mathbf{3 A}$ & 2.656 & 1.552 & 1.547 & 118.0 & 7.8 & 0.0 & 8.7 & 2.1 & 1981 & -218 & -5.1 \\
\hline 3a' & 3.409 & 1.495 & $\mathrm{n} / \mathrm{a}$ & $\mathrm{n} / \mathrm{a}$ & 0.9 & $0.0^{\mathrm{b}}$ & 7.7 & 6.8 & $\mathrm{n} / \mathrm{a}$ & $\mathrm{n} / \mathrm{a}$ & $\mathrm{n} / \mathrm{a}$ \\
\hline 3B & 3.135 & 1.498 & 2.509 & 99.8 & 1.4 & 1.1 & 4.5 & 1.6 & 2193 & $\mathrm{n} / \mathrm{c}^{\mathrm{c}}$ & -0.5 \\
\hline $3 b^{\prime}$ & 3.227 & 1.489 & $\mathrm{n} / \mathrm{a}$ & $\mathrm{n} / \mathrm{a}$ & 0.5 & $0.0^{\mathrm{b}}$ & 5.0 & 6.4 & $\mathrm{n} / \mathrm{a}$ & $\mathrm{n} / \mathrm{a}$ & $\mathrm{n} / \mathrm{a}$ \\
\hline $3 C$ & 2.696 & 1.551 & 1.615 & 116.7 & 7.1 & 1.9 & 6.9 & 2.1 & 1950 & -236 & -4.1 \\
\hline $3 c^{\prime}$ & 3.352 & 1.495 & $\mathrm{n} / \mathrm{a}$ & $\mathrm{n} / \mathrm{a}$ & 0.6 & $0.0^{\mathrm{b}}$ & 6.9 & 0.6 & $\mathrm{n} / \mathrm{a}$ & $\mathrm{n} / \mathrm{a}$ & $\mathrm{n} / \mathrm{a}$ \\
\hline 3D & 2.508 & 1.598 & 1.392 & 113.9 & 10.9 & 1.0 & 8.6 & 1.7 & 1875 & -317 & -13.8 \\
\hline 3d' & 3.275 & 1.494 & $\mathrm{n} / \mathrm{a}$ & $\mathrm{n} / \mathrm{a}$ & $0.0^{\mathrm{b}}$ & $0.0^{\mathrm{b}}$ & 7.3 & 5.1 & $\mathrm{n} / \mathrm{a}$ & $\mathrm{n} / \mathrm{a}$ & $\mathrm{n} / \mathrm{a}$ \\
\hline $4 \mathrm{~A}$ & 2.660 & 1.548 & 1.567 & 117.1 & 7.5 & 1.3 & 4.2 & 0.1 & 1991 & -184 & -3.9 \\
\hline $4 a^{\prime}$ & 3.411 & 1.498 & $\mathrm{n} / \mathrm{a}$ & $\mathrm{n} / \mathrm{a}$ & 0.8 & $0.0^{\mathrm{b}}$ & 2.3 & 8.8 & $\mathrm{n} / \mathrm{a}$ & $\mathrm{n} / \mathrm{a}$ & $\mathrm{n} / \mathrm{a}$ \\
\hline $4 B$ & 3.155 & 1.496 & 2.569 & 98.3 & 1.2 & 2.0 & 4.5 & 0.3 & $\sim 2200^{\mathrm{d}}$ & $\mathrm{n} / \mathrm{c}^{\mathrm{c}}$ & -0.6 \\
\hline $4 b^{\prime}$ & 3.223 & 1.493 & $\mathrm{n} / \mathrm{a}$ & $\mathrm{n} / \mathrm{a}$ & 0.4 & $0.0^{\mathrm{b}}$ & 3.4 & 8.3 & $\mathrm{n} / \mathrm{a}$ & $\mathrm{n} / \mathrm{a}$ & $\mathrm{n} / \mathrm{a}$ \\
\hline $4 C$ & 2.701 & 1.547 & 1.637 & 116.1 & 6.7 & 0.3 & 3.3 & 0.3 & 1962 & -212 & -3.0 \\
\hline $4 c^{\prime}$ & 3.368 & 1.499 & $\mathrm{n} / \mathrm{a}$ & $\mathrm{n} / \mathrm{a}$ & 0.5 & $0.0^{\mathrm{b}}$ & 1.1 & 4.7 & $\mathrm{n} / \mathrm{a}$ & $\mathrm{n} / \mathrm{a}$ & $\mathrm{n} / \mathrm{a}$ \\
\hline 4D & 2.495 & 1.595 & 1.391 & 113.2 & 10.8 & 2.5 & 6.3 & 0.7 & 1878 & -293 & -12.6 \\
\hline $4 d^{\prime}$ & 3.295 & 1.498 & $\mathrm{n} / \mathrm{a}$ & $\mathrm{n} / \mathrm{a}$ & $0.0^{\mathrm{b}}$ & $0.0^{\mathrm{b}}$ & 1.1 & 1.7 & $\mathrm{n} / \mathrm{a}$ & $\mathrm{n} / \mathrm{a}$ & $\mathrm{n} / \mathrm{a}$ \\
\hline
\end{tabular}

${ }^{a}$ Fully optimized open form taken as reference (note that this can be not fully reliable due to even a small rotation of the donor silyl group)

${ }^{b}$ Direct consequence of partial (constrained) geometry optimization

${ }^{\mathrm{c}}$ Not computed since the $-\mathrm{SiH}_{3}$ group rotates back upon the full geometry optimization

${ }^{\mathrm{d}}$ Three conjugated stretching modes in the $2200-2207-\mathrm{cm}^{-1}$ range

acute $\alpha_{\mathrm{SiHB}}$ angle $\left(103.4^{\circ}\right)$ and relatively high value of $\nu_{\mathrm{SiH}}$ $\left(2083 \mathrm{~cm}^{-1}\right)$ comparing to $\mathbf{3} \mathbf{A}_{\exp }\left(1919 \mathrm{~cm}^{-1}\right)$ where $\mathrm{Si}-$ $\mathrm{H} \cdot \mathrm{B}$ B was said to exist [4]. So high (absolute) value results, however, from experimental values of geometric parameters that do not correspond to fully optimized ones. Considerably lower values of $d_{\mathrm{Si} \cdots \mathrm{B}}(3.224 \AA), d_{\mathrm{H} \cdots \mathrm{B}}(2.647 \AA)$ and $d_{\mathrm{SiH}}(1.325 \AA)$ in $\mathbf{1} \mathbf{A}_{\exp }$ comparing to similar values in fully optimized $\mathbf{1 A}(3.276,2.712$ and $1.504 \AA$, respectively; Table 1) suggest significant packing forces in the former.
Importantly, the full geometry optimization of $\mathbf{1} \mathbf{A}_{\text {exp }}$ leads to modest lowering of its total energy than of $\mathbf{1} \mathbf{a}_{\text {exp }}$. As a consequence, the energy of the $\mathrm{H} \cdots \mathrm{B}$ contact in the fully optimized $\mathbf{1 A}$ is much lower, amounting to $-2.6 \mathrm{kcal} / \mathrm{mol}$ only. This value is even lower in $\mathbf{2 A}$ and amounts to $-1.7 \mathrm{kcal} / \mathrm{mol}$. Thus, if the $\mathrm{H} \cdots \mathrm{B}$ contacts in $\mathbf{1 A}$ and $\mathbf{2 A}$ are binding, they are indeed very weak as noted by Wrackmeyer et al. [4]. At this point, it is noteworthy that similar estimates for $\mathbf{3 A}$ and $\mathbf{4 A}$ have given energies of -5.1 and 
$-3.9 \mathrm{kcal} / \mathrm{mol}$, respectively (Table 1 ). Thus, the stabilizing character of the $\mathrm{H} \cdots \mathrm{B}$ contacts in both these systems is rather doubtless. This conclusion is in line with earlier spectroscopic results and the fact that, as we have shown in Fig. 7, the H. B interactions in both these systems are traced by corresponding bond paths, whereas similar bond paths are absent in case of the former two molecules, i.e. 1A and $\mathbf{2 A}$.

As Bader has stated, the presence of a bond path (on a molecular graph) and a concomitant bond critical point indicate stabilizing interaction $[33,34]$. On the other hand, however, a presumably binding interaction is not necessarily traced by a bond path $[60,61]$. As already discussed in the earlier subsection, apart from negative values of interaction energies, changes of geometrical parameters also indicate stabilizing character of $\mathrm{H} \cdots \mathrm{B}$ contacts in $\mathbf{1 A}$ and $\mathbf{2 A}$.

\section{Electronic and steric effects}

We have already shown that either clearly or presumably binding character of $\mathrm{H} \cdots \mathrm{B}$ contacts in $\mathbf{3 A}$ and $\mathbf{4 A}$ or $\mathbf{1 A}$ and $\mathbf{2 A}$, respectively, results from highly electrodonor properties of methyl groups present in $-\mathrm{SiMe}_{2} \mathrm{H}$. If they are substituted by hydrogens then the $\mathrm{H} \cdots \mathrm{B}$ contacts become hardly binding ( $\Delta E_{\text {int }}$ amounts to ca. $-0.5 \mathrm{kcal} / \mathrm{mol}$ only for all systems $\mathbf{n B} ; \mathbf{n}=\mathbf{1}-\mathbf{4})$. On the contrary, $\mathrm{Si} \cdots \mathrm{B}$ and $\mathrm{H} \cdots \mathrm{B}$

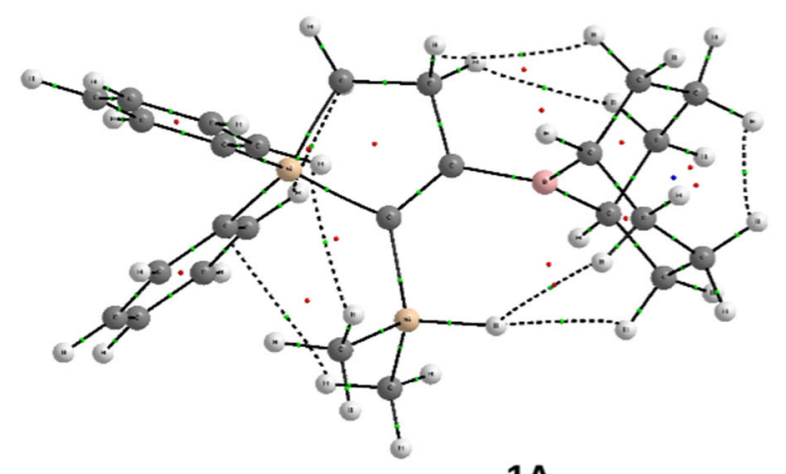

$1 \mathrm{~A}$

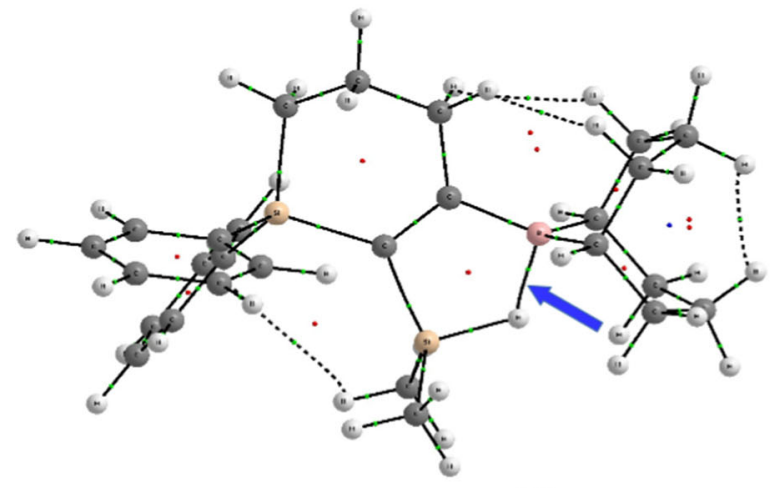

3A distances become much longer and the $\mathrm{Si}-\mathrm{H}$ bond becomes much shorter. Also, the $\alpha_{\mathrm{SiHB}}$ angle becomes more acute (and close to the right angle) indicating that $\mathrm{Si}-\mathrm{H}$ and $\mathrm{C}-$ B bonds are almost parallel to each other (see also Fig. 6). Another evidence of much weaker interactions in $\mathbf{~} \mathbf{B}$ comparing to $\mathbf{n A}$ are higher values of $\nu_{\mathrm{SiH}}$ in the former. All these effects are particularly evident in respective pairs of 1-silacyclohex-2-enes.

It should be mentioned that the bulky 9-BBN group in $\mathbf{n A}$ and $\mathbf{n B}$ is not completely advantageous in our estimations of $\Delta E_{\text {int }}$ in these systems because of possible $\mathrm{H} \cdots \mathrm{H}$ repulsions in their na' and nb' open forms (Fig. 6). For this reason, we suspect that values of $\Delta E_{\text {int }}$ obtained for these systems may be somewhat overestimated (Fig. 4). Nevertheless, both qualitative results as well as relations among computed values should be proper since the same structural changes, and thus, interatomic interactions occur in all pairs of open and closed forms. Moreover, all (9$\mathrm{BBN}) \mathrm{H} \cdots \mathrm{H}\left(\mathrm{SiMe}_{2} \mathrm{H}\right)$ or $(9-\mathrm{BBN}) \mathrm{H} \cdots \mathrm{H}\left(\mathrm{SiH}_{3}\right)$ distances are longer than ca. 2.15 or $2.42 \AA$ found in $\mathbf{4 a}$ ' and $\mathbf{4 b}$ ', respectively, suggesting that repulsions are rather negligible as being no larger than ca. $0.5 \mathrm{kcal} / \mathrm{mol}$ (MP2/aug-ccpVTZ) [31].

To eliminate the bulky 9-BBN group, we have considered $\mathbf{n C}$ systems possessing the $-\mathrm{BMe}_{2}$ group in place of 9-BBN (Fig. 5). Although this small group should reduce $\mathrm{H} \cdots \mathrm{H}$ repulsions in open nc' forms (the shortest $\mathrm{H} \cdots \mathrm{H}$
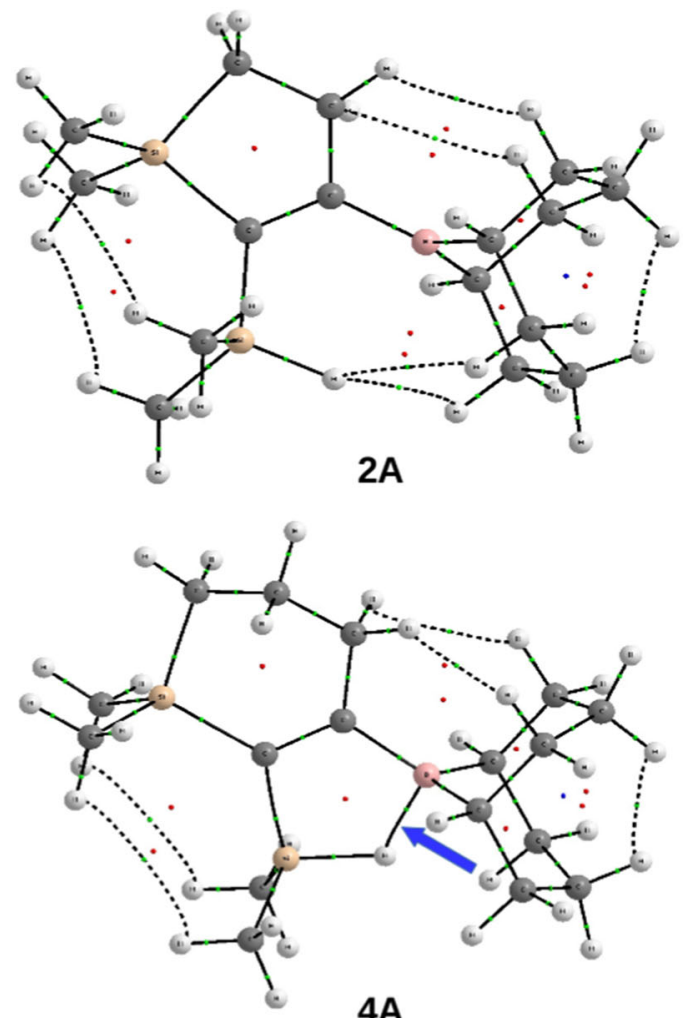

Fig. 7 Molecular graphs of 1A, 2A, 3A and 4A. Note H $\cdots$ B bond paths (indicated by blue arrow) in the latter two molecules 
distances are ca. $2.4 \AA$ in $\mathbf{1} \mathbf{c}^{\prime}$ and $\mathbf{4} \mathbf{c}^{\prime}$ and ca. $2.5 \AA$ in $\mathbf{2} \mathbf{c}^{\prime}$ and $\left.\mathbf{3} \mathbf{c}^{\prime}\right)$, on the other hand, it should lead to weaker $\mathrm{Si}_{-}$ $\mathrm{H} \cdots \mathrm{B}$ bridges due to certain electron density shift from both methyl groups of $-\mathrm{BMe}_{2}$ to the formally empty $2 p$ orbital on B. Indeed, in the case of both 1-silacyclohex-2enes, the interaction energy decreases from $-5.1 \mathrm{kcal} / \mathrm{mol}$ in $\mathbf{3 A}$ to $-4.1 \mathrm{kcal} / \mathrm{mol}$ in $\mathbf{3 C}$ and from $-3.9 \mathrm{kcal} / \mathrm{mol}$ in $4 \mathrm{~A}$ to $-3.0 \mathrm{kcal} / \mathrm{mol}$ in $\mathbf{4 C}$ (Table 1 ). Weakening of the relevant $\mathrm{H} \cdots \mathrm{B}$ interactions is also reflected in lower values of electron density at bond critical points of these interactions $\left(\rho_{\mathrm{b}}\right)$. They amount to 0.063 and 0.055 au in $\mathbf{3 A}$ and 3C, respectively, whereas 0.060 and 0.053 au in $\mathbf{4 A}$ and 4C, respectively. In addition to the electron density, also, the delocalization index $[62,63]$ of $\mathrm{H}$ and $\mathrm{B}$ atoms (which is a measure of the number of electron pairs shared by these two atomic basins), $\mathrm{DI}(\mathrm{H}, \mathrm{B})$, decreases as expected (from 0.206 au in $\mathbf{3 A}$ to 0.183 au in $\mathbf{3 C}$ and from 0.198 au in $\mathbf{4 A}$ to 0.175 au in $4 \mathrm{C})$. Larger values of both $\rho_{\mathrm{b}}$ and $\mathrm{DI}(\mathrm{H}, \mathrm{B})$ in the former pair of molecules also indicate that $\mathrm{H} \cdots \mathrm{B}$ interactions should be stronger in $\mathbf{3 A}$ and $\mathbf{3 C}$ than in $\mathbf{4 A}$ and $\mathbf{4 C}$. This suggestion is in line with our estimates of $\Delta E_{\text {int }}$. Similar decreases of $\Delta E_{\text {int }}$ are, however, not observed for both 1-silacyclopent-2-enes, for which $\Delta E_{\text {int }}$ is either the same $\left(\mathbf{1 A} \rightarrow \mathbf{1 C} ; \Delta E_{\mathrm{int}}=-2.6 \mathrm{kcal} / \mathrm{mol}\right)$ or slightly increases (from $-1.7 \mathrm{kcal} / \mathrm{mol}$ in $\mathbf{2 A}$ to $-2.1 \mathrm{kcal} / \mathrm{mol}$ in $\mathbf{2 C}$ ). This indicates that our estimates of $\Delta E_{\text {int }}$ are more reliable for 1-silacyclohex-2-enes than those for 1-silacyclopent-2-enes and may most likely result from considerably higher values of $\Delta E_{\text {int }}$ for the former group of systems.

In turn, to eliminate the electron donating properties of methyl groups in $-\mathrm{BMe}_{2}$, we have also investigated systems $\mathbf{n D}$ (and nd') possessing $-\mathrm{BH}_{2}$ in place of $-\mathrm{BMe}_{2}$ (Fig. 5). Moreover, this substitution further reduces $\mathrm{H} \cdots \mathrm{H}$ interactions in open reference forms. On the other hand, however, the $-\mathrm{BH}_{2}$ group is prone to rotate around the C-B bond (going in plane) so as to possibly form dihydrogen bond and to conjugate with the $\mathrm{C}=\mathrm{C}$ bond of the ring. For this reason, the open reference nd' systems have been obtained by freezing not only $\theta_{\mathrm{HSiCC}}$ (at $180^{\circ}$ ) but $\theta_{\mathrm{HBCC}}$ as well (at $\pm 90^{\circ}$ ). Thus, $-\mathrm{BH}_{2}$ in nd' was kept perpendicularly to the BCC plane. Since the $\mathbf{n D}$ systems feature rather significant pyramidalization of the $-\mathrm{BH}_{2}$ fragment ( $P$ amounts to ca. $10^{\circ}$ in $1 \mathrm{D}$ and 2D and ca. $11^{\circ}$ in $3 \mathrm{D}$ and $\mathbf{4 D}$; Table 1 ), the pyramidalization energy, i.e. the energy that is needed to deform flat $-\mathrm{BH}_{2}$ group in nd' to its somewhat pyramidal shape in $\mathbf{n D}$, is included in our estimates of $\Delta E_{\text {int. }}$ As discussed in the 'Energy of an intramolecular interaction' section, this and other (small) deformations are, however, consequences of the $\mathrm{H} \cdots \mathrm{B}$ interactions in the $\mathbf{n D}$ closed forms. As expected, one obtains considerably high values of $\Delta E_{\text {int }}$.
In 1D and 2D 1-silacyclopent-2-enes, they have been estimated as ca. $-10 \mathrm{kcal} / \mathrm{mol}$, whereas in both 1-silacyclohex2-enes, $\Delta E_{\text {int }}$ are higher amounting to $-13.8 \mathrm{kcal} / \mathrm{mol}$ in 3D and $-12.6 \mathrm{kcal} / \mathrm{mol}$ in $4 \mathrm{D}$. So high values of $\Delta E_{\text {int }}$ are in line with relatively large values of $\rho_{\mathrm{b}}$ (ca. 0.08 au for all $\mathbf{~} D$ systems). It is noteworthy that among all $\mathbf{1 L}$ and $\mathbf{2 L}$ $(\mathbf{L}=\mathbf{A}-\mathbf{D})$ only $\mathbf{1 D}$ and $\mathbf{2 D}$ feature a $\mathrm{H} \cdots \mathrm{B}$ bond path. Moreover, also, DI $(\mathrm{H}, \mathrm{B})$ values are rather high $(0.291$ au for 1D and 2D and 0.297 au for 3D and 4D). The characteristic feature of these systems is that $d_{\mathrm{SiH}}>d_{\mathrm{H} \cdots \mathrm{B}}$ (Table 1), indicating a highly advanced transfer of $\mathrm{H}$ toward B. Similar effect has also been reported [18] in $\mathrm{H}_{3} \mathrm{SiH} \cdots \mathrm{BH}_{3}$ (better written as $\mathrm{H}_{3} \mathrm{Si} \cdot \cdots \mathrm{H}_{2} \cdot \mathrm{BH}_{2}$ ). Interestingly, reported binding energy of this dimer amounts to $-11.7 \mathrm{kcal} / \mathrm{mol}$ (MP2/aug-cc-pVTZ) [18]—closely to our estimates for $\mathbf{n D}$.

\section{Conclusions}

The main purpose of this article is to assess strengths of $\mathrm{H} \cdots \mathrm{B}$ contacts in some 1-silacyclopent-2-enes and 1-silacyclohex-2-enes investigated earlier by Wrackmeyer et al. [4]. For this purpose, we have computed interaction energies of these contacts utilizing so-called openclosed method. In full agreement with previous conclusions based on NMR spectroscopic data [4], we have shown that the $\mathrm{H} \cdots \mathrm{B}$ contacts in investigated 1-silacyclohex-2-enes are indeed strong, whereas those in 1-silacyclopent-2-enes are much weaker. This result is supported by appropriate changes of geometrical parameters that take place upon the open form $\rightarrow$ closed form transformation and by reported values of some QTAIM-based parameters.

Influence of both the electronic and steric effects originating from the presence of specific substituents on the strength of relevant $\mathrm{H} \cdots \mathrm{B}$ contacts is discussed in detail. We have shown that relatively strong $\mathrm{H} \cdots \mathrm{B}$ interactions found in both 1-silacyclopent-2-enes and 1-silacyclohex2-enes result from the presence of two methyl groups in $-\mathrm{SiMe}_{2} \mathrm{H}$. If they are substituted by hydrogens, then $\mathrm{H} \cdots \mathrm{B}$ interactions become hardly bonding. On the other hand, if the 9-BBN group is subsituted by $-\mathrm{BH}_{2}$, then the investigated $\mathrm{Si}-\mathrm{H} \cdots \mathrm{B}$ bridges feature many of the characteristic effects attesting to their considerable strength as also shown by high values of interaction energies and QTAIM-based parameters.

Some problems and ideas associated with the use of the open-closed method are discussed in detail. In particular, we have paid attention to the correct choice of the reference open system. It has been shown that utilization of the partial geometry optimization of the reference open system leads to reliable results. 
Open Access This article is distributed under the terms of the Creative Commons Attribution 4.0 International License (http:// creativecommons.org/licenses/by/4.0/), which permits unrestricted use, distribution, and reproduction in any medium, provided you give appropriate credit to the original author(s) and the source, provide a link to the Creative Commons license, and indicate if changes were made.

Acknowledgements The National Science Centre of Poland is gratefully acknowledged for the financial support grant no. 2015/17/B/ST4/04050. We thank Dr. Marcin Palusiak from the University of Łódź for the search in the Cambridge Structural Database.

\section{Compliance with ethical standards}

Conflict of interest The author declares that he has no conflict of interest.

\section{References}

1. Wrackmeyer B, Tok OL, Bubnov YN (1999) The first Si-H-B bridge: combination of 1,1-organoboration and hydrosilylation. Angew Chem Int Ed 38:124-126

2. Wrackmeyer B, Milius W, Tok OL (2003) Reaction of alkyn1-yl(diorganyl)silanes with 1-boraadamantane: $\mathrm{Si}-\mathrm{H}-\mathrm{B}$ bridges confirmed by the molecular structure in the solid state and in solution. Chem Eur J 9:4732-4738

3. Wrackmeyer B, Tok OL, Khan A, Badshah A (2005) 1,1Organoboration of silylethynyltin compounds studied by multinuclear magnetic resonance spectroscopy: isomerization at the $\mathrm{C}=\mathrm{C}$ bonds and electron-decient $\mathrm{Si}-\mathrm{H}-\mathrm{B}$ bridges. Appl Organometal Chem 19:1249-1256

4. Wrackmeyer B, Tok OL, Milius W, Khan A, Badshah A (2006) 1-Silacyclopent-2-enes and 1-silacyclohex-2-enes bearing functionally substituted silyl groups in 2-positions. Novel electrondeficient $\mathrm{Si}-\mathrm{H}-\mathrm{B}$ bridges. Appl Organometal Chem 20:99-105

5. Schubert U (1990) $\eta^{2}$ Coordination of $\mathrm{Si}-\mathrm{H} \sigma$ Bonds to Transition Metals. Adv Organomet Chem 30:151-187

6. Kubas GJ (2001) Metal Dihydrogen and $\sigma$-Bond Complexes. Kluwer Academic/Plenum Publisher, New York

7. Clot E, Eisenstein O (2004) Agostic Interactions from a Computational Perspective: One Name, Many Interpretations. Struct Bonding (Berlin) 113:1-36

8. Lin Z (2002) Structural and bonding characteristics in transition metal-silane complexes. Chem Soc Rev 31:239-245

9. Lein M (2009) Characterization of Agostic Interactions in Theory and Computation. Coord Chem Rev 253:625-634

10. Schneider JJ (1996) $\mathrm{Si}-\mathrm{H}, \mathrm{C}-\mathrm{H}$ Activation by transition metal complexes: a step towards isolable alkane complexes Angew Chem Int Ed Engl 35:1068-1075

11. Jabłoński M (2015) QTAIM-Based Comparison of Agostic Bonds and Intramolecular Charge-Inverted Hydrogen Bonds. J Phys Chem A 119:4993-5008

12. Jabłoński M (2015) Geometry- and QTAIM-Based Comparison of Intramolecular Charge-Inverted Hydrogen Bonds, $\mathrm{M} \cdots(\mathrm{H}-\mathrm{Si})$ "Agostic Bond", and $\mathrm{M} \cdots\left(\eta^{2}-\mathrm{SiH}\right) \sigma$ Interactions. J Phys Chem A 119:11384-11396

13. Jabłoński M (2016) Comparative study of geometric and QTAIMbased differences between $\mathrm{X}-\mathrm{H} \cdots \mathrm{Y}$ intramolecular chargeinverted hydrogen bonds, $\mathrm{M}_{1} \cdots(\mathrm{H}-\mathrm{X})$ agostic bonds and
$\mathrm{M}_{2} \cdots\left(\eta^{2}-\mathrm{XH}\right) \sigma$ interactions $\left(\mathrm{X}=\mathrm{Si}, \mathrm{Ge} ; \mathrm{Y}=\mathrm{Al}, \mathrm{Ga} ; \mathrm{M}_{1}=\mathrm{Ti}\right.$, $\left.\mathrm{Co} ; \mathrm{M}_{2}=\mathrm{Mn}, \mathrm{Fe}, \mathrm{Cr}\right)$. Comput Theor Chem 1096:54-65

14. Choi SH, Feng J, Lin Z. (2000) Understanding the Readiness of Silane Dissociation in Transition Metal $\eta^{2}$-Silane Complexes $\mathrm{Cp}(\mathrm{CO})_{2} \mathrm{M}\left[\eta^{2}-\mathrm{H}\left(\mathrm{SiH}_{3 n} \mathrm{Cl}_{n}\right)\right](\mathrm{M}=\mathrm{Mn}$, Tc, and Re; $n=1-3)$. Organometallics 19:2051-2054

15. McGrady GS, Sirsch P, Chatterton N, Ostermann A, Gatti C, Altmannshofer S, Herz V, Eickerling G, Scherer W (2009) Nature of the Bonding in Metal-Silane $\sigma$-Complexes. Inorg Chem 48:1588-1598

16. Jabłoński M (2016) Systematic studies of the influence of electronegative $\mathrm{X}(\mathrm{X}=\mathrm{F}$ and $\mathrm{Cl})$ substituents on the structure of the $\mathrm{Mn}-\mathrm{H}-\mathrm{Si}$ unit and the strength of the $\mathrm{Mn} \cdots\left(\eta^{2}-\mathrm{SiH}\right) \sigma$ interaction in $\mathrm{Cp}(\mathrm{OC})_{2} \mathrm{Mn}\left[\eta^{2}-\mathrm{H}\left(\mathrm{SiH}_{3-n} X_{n}\right)\right](n=0-3)$ complexes. Comput Theor Chem 1076:51-56

17. Jabłoński M (2016) Conciliatory Inductive Model Explaining the Origin of Changes in the $\eta^{2}-\mathrm{SiH}$ Bond Length Caused by Presence of Strongly Electronegative Atoms $\mathrm{X}(\mathrm{X}=\mathrm{F}, \mathrm{Cl})$ in $\mathrm{Cp}(\mathrm{OC})_{2} \mathrm{Mn}\left[\eta^{2}-\mathrm{H}\left(\mathrm{SiH}_{3-n} X_{n}\right)\right](n=0-3)$ Complexes. J Phys Chem A 120:4211-4222

18. Jabłoński M (2009) Binding of X-H to the lone-pair vacancy: Charge-inverted hydrogen bond. Chem Phys Lett 477:374-376

19. Jabłoński M (2010) Full vs. constrain geometry optimization in the open-closed method in estimating the energy of intramolecular charge-inverted hydrogen bonds. Chem Phys 376:76-83

20. Jabłoński M (2010) Intramolecular charge-inverted hydrogen bond. J Mol Struct: THEOCHEM 948:21-24

21. Jabłoński M (2012) Theoretical insight into the nature of the intermolecular charge-inverted hydrogen bond. Comput Theor Chem 998:39-45

22. Jabłoński M, Sokalski WA (2012) Physical nature of interactions in charge-inverted hydrogen bonds. Chem Phys Lett 552:156-161

23. Jabłoński M (2014) Charge-inverted hydrogen bond vs. other interactions possessing a hydridic hydrogen atom. Chem Phys 433:76-84

24. Udagawa T, Tachikawa M (2015) H/D Isotope Effect on ChargeInverted Hydrogen-Bonded Systems: Systematic classification of three different types in $\mathrm{H}_{3} \mathrm{XH} \cdots \mathrm{YH}_{3}(\mathrm{X}=\mathrm{C}, \mathrm{Si}$, or $\mathrm{Ge}$, and $\mathrm{Y}=$ $\mathrm{B}, \mathrm{Al}$, or $\mathrm{Ga}$ ) with Multicomponent Calculation. J Comput Chem 36:1647-1654

25. Yourdkhani S, Jabłoński M (2017) Revealing the Physical Nature and the Strength of Charge-Inverted Hydrogen Bonds by SAPT(DFT), MP2, SCS-MP2, MP2C, and CCSD(T) Methods, J Comput Chem 38:773-780

26. Buemi G, Grabowski SJ (eds) (2006) Hydrogen Bonding-New insights, vol 3. Springer, Dordrecht, The Netherlands

27. Craw JS, Bacskay GB (1992) Quantum-chemical Studies of Hydrogen Bonding involving Thioxoketones, Thienols, Thioformaldehyde and Hydrogen Sulfide with Specific Reference to the Strength of Intramolecular Hydrogen Bonds. J Chem Soc Faraday Trans 88:2315-2321

28. Buemi G, Zuccarello F (2002) Is the intramolecular hydrogen bond energy valuable from internal rotation barriers J Mol Struct (Theochem) 581:71-85

29. Jabłoński M, Kaczmarek A, Sadlej AJ (2006) Estimates of the Energy of Intramolecular Hydrogen Bonds. J Phys Chem A 110:10890-10898

30. Jabłoński M (2012) Energetic and Geometrical Evidence of Nonbonding Character of Some Intramolecular Halogen ... Oxygen and Other Y...Y Interactions. J Phys Chem A 116:37533764

31. Jabłoński M, Monaco G (2013) Different Zeroes of Interaction Energies As the Cause of Opposite Results on the Stabilizing 
Nature of C-H. . O Intramolecular Interactions. J Chem Inf Model 53:1661-1675

32. Frisch MJ, Trucks GW, Schlegel HB, Scuseria GE, Robb MA, Cheeseman JR, Scalmani G, Barone V, Mennucci B, Petersson GA, Nakatsuji H, Caricato M, Li X, Hratchian HP, Izmaylov AF, Bloino J, Zheng G, Sonnenberg JL, Hada M, Ehara M, Toyota K, Fukuda R, Hasegawa J, Ishida M, Nakajima T, Honda Y, Kitao O, Nakai H, Vreven T, Montgomery JA, Peralta Jr JE, Ogliaro F, Bearpark M, Heyd JJ, Brothers E, Kudin KN, Staroverov VN, Keith T, Kobayashi R, Normand J, Raghavachari K, Rendell A, Burant JC, Iyengar SS, Tomasi J, Cossi M, Rega N, Millam JM, Klene M, Knox JE, Cross JB, Bakken V, Adamo C, Jaramillo J, Gomperts R, Stratmann RE, Yazyev O, Austin AJ, Cammi R, Pomelli C, Ochterski JW, Martin RL, Morokuma K, Zakrzewski VG, Voth GA, Salvador P, Dannenberg JJ, Dapprich S, Daniels AD, Farkas O, Foresman JB, Ortiz JV, Cioslowski J, Fox DJ Gaussian 09, Gaussian, Inc., Wallingfor

33. Bader RFW (1990) Atoms in Molecules: A Quantum Theory. Oxford University Press, New York

34. Popelier PLA (2000) Atoms in Molecules. An Introduction. Longman, Singapore

35. Matta CF, Boyd RJ (2007) The Quantum Theory of Atoms in Molecules. Wiley-VCH, Weinheim

36. Keith TA (2015) AIMAll (Version 15.05.18), TK Gristmill Software, Overland Park KS, USA, ;aim.tkgristmill.com;

37. Perdew JP, Burke K, Ernzerhof M (1996) Generalized gradient approximation made simple. Phys Rev Lett 77:3865-3868

38. Perdew JP, Burke K, Ernzerhof M (1997) Errata: generalized gradient approximation made simple. Phys Rev Lett 78: 1396

39. Adamo C, Barone V (1999) Toward reliable density functional methods without adjustable parameters: the PBE0 model. J Chem Phys 110:6158-6170

40. Krishnan R, Binkley JS, Seeger R, Pople JA (1980) Self-consistent molecular orbital methods. XX. A basis set for correlated wave functions. J Chem Phys 72(1980):650-654

41. McLean AD, Chandler GS (1980) Contracted Gaussian basis sets for molecular calculations. I. Second row atoms, $Z=11-18$. J Chem Phys 72:5639-5648

42. Zyder M, Kochel A, Handzlik J, Szymanska-Buzar T (2009) Photochemical reaction of $\mathrm{Mo}(\mathrm{CO})_{6}$ with $\mathrm{Et}_{2} \mathrm{GeH}_{2}$ : NMR and DFT studies of reaction products; crystal structure of a novel complex $\left[\left\{\mathrm{Mo}\left(\mu-\eta^{2}-\mathrm{H}-\mathrm{GeEt}_{2}\right)(\mathrm{CO})_{4}\right\}_{2}\right]$. Organometallics 28:58575865

43. Tognetti V, Joubert L (2011) On the influence of density functional approximations on some local Bader's atoms-in-molecules properties. J Phys Chem A 115:5505-5515

44. Medvedev MG, Bushmarinov IS, Sun J, Perdew JP, Lyssenko KA (2017) Density functional theory is straying from the path toward the exact functional. Science 355:49-52

45. Schuster P (1969) LCAO-MO-Beschreibung intramolekularer Wasserstoffbrücken. Mh Chem 100:2084-2095
46. Schuster P, Schuster P, Zundel G, Sandorfy C (eds) (1976) The Hydrogen Bond, vol I. North-Holland, Amsterdam

47. Emsley J (1984) The Composition, Structure and Hydrogen Bonding of the $\beta$-Diketones. Struct Bond 57:147-191

48. Buemi G, Gandolfo C (1989) Malondialdehyde and Acetylacetone: An AM1 Study of their Molecular Structures and Keto-Enol Tautomerism. J Chem Soc. Faraday Trans 85:215-227

49. Millefiori S, Di Bella S (1991) Hydrogen bonding and tautomerism in 3-substituted $\beta$-thioxoketones: an ab initio molecular orbital study. J Chem Soc. Faraday Trans 87:1297-1302

50. Luth K, Scheiner S (1994) Excited-State Energetics and ProtonTransfer Barriers in Malonaldehyde. J Phys Chem 98:3582-3587

51. Scheiner S, Kar T, C̆uma M (1997) Excited State Intramolecular Proton Transfer in Anionic Analogues of Malonaldehyde. J Phys Chem A 101:5901-5909

52. Cuma M, Scheiner S, Kar T (1999) Effect of adjoining aromatic ring upon excited state proton transfer, o-hydroxybenzaldehyde. J Mol Struct (Theochem) 467:37-49

53. Chung G, Kwon O, Kwon Y (1997) Theoretical Study on 1,2-Dihydroxybenzene and 2-Hydroxythiophenol: Intramolecular Hydrogen Bonding. J Phys Chem A 101:9415-9420

54. Rozas I, Alkorta I, Elguero J (2001) Intramolecular Hydrogen Bonds in ortho-Substituted Hydroxybenzenes and in 8-Susbtituted 1-Hydroxynaphthalenes: Can a Methyl Group Be an Acceptor of Hydrogen Bonds J Phys Chem A 105:10462-10467

55. Kovács A, Szabó A, Hargittai I (2002) Structural Characteristics of Intramolecular Hydrogen Bonding in Benzene Derivatives. Acc Chem Res 35:887-894

56. Grabowski SJ (2003) $\pi$-Electron delocalisation for intramolecular resonance assisted hydrogen bonds. J Phys Org Chem 16:797-802

57. Grabowski SJ (2004) Hydrogen bonding strength-measures based on geometric and topological parameters. J Phys Org Chem $17: 18-31$

58. Estácio SG, do Couto PC, Costa Cabral BJ, Minas da Piedade ME, Martinho Simões JA (2004) Energetics of Intramolecular Hydrogen Bonding in Di-substituted Benzenes by the ortho-para Method. J Phys Chem A 108:10833-10843

59. Groom CR, Bruno IJ, Lightfoot MP, Ward SC (2016) The Cambridge Structural Database. Acta Cryst B72:171-179

60. Popelier PLA, Logothetis G (1998) Characterization of an Agostic Bond on the Basis of the Electron Density. J Organomet Chem 555:101-111

61. Tognetti V, Joubert L, Raucoules R, De Bruin T, Adamo C (2012) Characterizing Agosticity Using the Quantum Theory of Atoms in Molecules: Bond Critical Points and Their Local Properties. J Phys Chem A 116:5472-5479

62. Fradera X, Austen MA, Bader RFW (1999) The Lewis Model and Beyond. J Phys Chem A 103:304-314

63. Wang YG, Matta C, Werstiuk NH (2003) Comparison of Localization and Delocalization Indices Obtained with Hartree-Fock and Conventional Correlated Methods: Effect of Coulomb Correlation. J Comput Chem 24:1720-1729 